\title{
Diabetic Ketoacidosis Linked with Sodium Glucose Co-Transporter 2 Inhibitors in an Elderly Patient with Type 2 Diabetes
}

\author{
Jose G Jimenez-Montero* \\ Department of Endocrinology, CIMA Hospital and Medical School, Universidad de Ciencias Médicas, Costa Rica
}

*Corresponding author: Jose G Jimenez-Montero, Department of Endocrinology, CIMA Hospital and Medical School, Universidad de Ciencias Médicas, Costa Rica, Tel: 506 22081301; E-mail: jjimenez@hospitalcima.com

Received: 25 Mar, 2019 | Accepted: 24 Apr, 2019 | Published: 30 Apr, 2019

Citation: Jimenez-Montero JG (2019) Diabetic Ketoacidosis Linked with Sodium Glucose Co-Transporter 2 Inhibitors in an Elderly Patient with Type 2 Diabetes. Int J Endocrinol Metab Disord 5(1): dx.doi.org/10.16966/2380-548X.154

Copyright: (C) 2019 Jimenez-Montero JG. This is an open-access article distributed under the terms of the Creative Commons Attribution License, which permits unrestricted use, distribution, and reproduction in any medium, provided the original author and source are credited.

\begin{abstract}
Objective: To report an episode of diabetic ketoacidosis and acute kidney failure in a patient with type 2 diabetes (T2DM) recently initiated a sodiumglucose co-transporter 2 inhibitor (SGLT-2i) and a DDPP-4 inhibitor (DDP-4i).

Methods: We describe the clinical presentation, laboratory data and management of an elderly T2DM patient with diabetic ketoacidosis.

Results: A 80 year-old T2DM female presented with, fatigue, nausea, recurrent vomiting, muscle pain, malaise and shortness of breath three weeks after initiation of dapagliflozin $5 \mathrm{mg}$ and sitagliptin $100 \mathrm{mg}$. On admission to the emergency department, the patient was hypotensive, and rapidly became comatose. The glucose concentration was $398 \mathrm{mg} / \mathrm{dL}, \mathrm{Na} 135 \mathrm{mmol} / \mathrm{L}, \mathrm{K} 4.1 \mathrm{mmol} / \mathrm{L}, \mathrm{pH} 6.8$, and bicarbonate $1.8 \mathrm{mmol} / \mathrm{L}$, blood urea nitrogen $22.8 \mathrm{mg} / \mathrm{dL}$, creatinine $0.96 \mathrm{mg} / \mathrm{dL}$, beta-hydroxybutirate $3.2 \mathrm{mmol} / \mathrm{L}$ and lactate $1.1 \mathrm{mmol} / \mathrm{L}$. The estimated osmolality was 300.25 $\mathrm{mOsm} / \mathrm{L}$ and the anion gap $26.7 \mathrm{mEq} / \mathrm{L}$. C-reactive protein was $<2.5 \mathrm{mg} / \mathrm{L}$. Urine sample was normal and urine culture was negative. Hemoglobin was $12.6 \mathrm{~g} / \mathrm{dL}$; leucocyte count was $21.0 \times 10^{3} \mu \mathrm{L}$ and platelet count $253 \times 10^{3} \mu \mathrm{L}$. Two days after hospitalisation the patient developed an acute kidney failure and anemia. The patient was treated with balanced electrolyte solutions, continuous insulin infusion and IV antibiotics and dapagliflozin was discontinued. Diabetic ketoacidosis resolved in 48 hours and the acute kidney failure in 6 days. The patient was discharged 10 days after admission with a basal bolus regimen with insulin analogues.
\end{abstract}

Conclusions: This elderly patient with long lasting type 2 diabetes treated with SGLT-2i developed diabetic ketoacidosis and acute kidney failure. This complication occurred associated with dietary derangements and lack of insulin treatment. Each medication change needs a very clear indication; otherwise it adds more risk to the patient than benefit. When prescribing SGLT2i in diabetics, physician must assure diabetes education, an adequate insulin provision and strict monitoring of glucose and urine ketones.

Keywords: Diabetes ketoacidosis; Type 1 diabetes; SGLT2 inhibitors

\section{Introduction}

Diabetic Ketoacidosis (DKA) is a serious and potentially lifethreatening condition, which mainly occurs in Type 1 Diabetes Mellitus (T1DM). In T2DM, DKA may appear particularly in the presence of insulin deficiency associated with increased insulin requirements. SGLT-2i is novel anti-hyperglycaemic agents, which block glucose reabsorption in the proximal renal tubule enhancing urinary glucose excretion and lowering plasma glucose concentrations with few side effects [1-4]. These agents have been indicated as monotherapy, or combined with other oral agents, as well with insulin for the treatment of T2DM patients [5]. In T2DM, SGLT2i reduces fasting, postprandial glucose and $\mathrm{HbAlc}$ levels between 0.3 to $1.2 \%$ with low rates of hypoglycaemia [6].

Besides from its glucose lowering effects, these drugs induce weight loss between 1.5-3.0 kg, and add positive effects on blood pressure, uric acid levels, cardiovascular mortality and renal benefits in highrisk patients with T2DM [7-9].

Adverse effects of SGLT2i include genital fungal and urinary tract infections $[9,10]$. Special attention must be paid when prescribing this medication to frail patients who are more susceptible to postural hypotension, dehydration, and dizziness, for instance in those receiving diuretics [5]. The US Food and Drug Administration has delivered reports warning that usage of SGLT2 inhibitors may be linked with an augmented risk of DKA in both T1DM and T2DM patients [11]. This complication has been observed in the context of certain predisposing factors, which includes reduction in insulin provision, infections, surgery, alcohol intake and dietary derangements [11-16].

\section{Case Presentation}

An 80 year-old female non-obese T2DM with hypertension, dyslipidaemia and peripheral neuropathy developed DKA while 
Table 1: Pertinent Laboratory Results in the patient with DKA.

\begin{tabular}{|l|c|c|}
\hline \multicolumn{1}{|c|}{ Case } & Initial & Reference value \\
\hline Glycemia $(\mathrm{mg} / \mathrm{dL})$ & 398 & $70-100$ \\
\hline $\mathrm{pH}$ & 6.8 & $7.35-7.45$ \\
\hline $\mathrm{pO}_{2}(\mathrm{mmHg})$ & 117.4 & $75-100$ \\
\hline $\mathrm{pCO}_{2}(\mathrm{mmHg})$ & 11.7 & 13.9 \\
\hline Bicarbonate $(\mathrm{mmol} / \mathrm{L})$ & 1.8 & $22-26$ \\
\hline Ketonuria $(\mathrm{mg} / \mathrm{dL})$ & 150 & 0 \\
\hline Beta hydroxibytirate (mmol/L) & 3.2 & less than 0.6 \\
\hline Lactate (mmol/L) & 1.1 & $1.0-1.7$ \\
\hline BUN (mg/dL & 22.8 & $7.9-20.1$ \\
\hline Creatinine & 0.96 & $0.62-1.3$ \\
\hline Na (mEq/L) & 135 & $135-145$ \\
\hline $\mathrm{K}$ (mEq/L) & 4.1 & $3.5-5.1$ \\
\hline Cloride (mEq/L) & 106.5 & $98-107$ \\
\hline Calium & 8.1 & $8.6-10.1$ \\
\hline Osmolality (mOsm/Kg) & 300.25 & Aug-16 \\
\hline Anion Gap (mEq/L) & 26.7 & $1.0-10.0$ \\
\hline
\end{tabular}

traveling in a crusse-ship through the Caribbean. Three weeks before during a medical evaluation performed by a general doctor, her usual treatment, which consisted of glimepiride and metformin, was changed to sitagliptin $100 \mathrm{mg}$ and dapagliflozin $5 \mathrm{mg}$ because the glycosylated haemoglobin Alc was $10.3 \%$. The patient also received losartan $50 \mathrm{mg}$ and simvastatin $20 \mathrm{mg}$ daily. With the change of the antihyperglycemic agents there was no improvement in glycaemic control. However, the patient was able to maintain normal daily routine activities. While in the ship the patient decided to eat salads, meats, drank water, sugar free refreshments and occasionally alcoholic beverages. Twelve hours before admission the patient presented epigastric pain, nausea, vomiting, malaise, fatigue and muscle pain. The patient gradually became hypotensive and comatose. She was treated with two litres of saline solutions. In the evening of that day the patient was airlifted to the Emergency Department of a General Hospital in San José, Costa Rica. On arrival at the public general hospital the heart rate was 120 beats per minute, respiratory frequency $16 /$ min with profound respiration. The patient was a febrile and her blood pressure was 108/65 mmHg. Heart sounds were rhythmic and lungs were clear. The abdomen was soft without masses with normal peristaltic movements. Haemoglobin was $12.6 \mathrm{~g} / \mathrm{dL}$, leucocyte count was $21.0 \times 10^{3} \mu \mathrm{L}$ and platelet count $253 \times 10^{3} \mu \mathrm{L}$. Liver function tests, $\mathrm{C}$-reactive protein, troponins were negative. The urine smear showed eritrocyturia, abundant bacteria and 10 leucocytes per field. Urine and blood cultures became negative. The electrocardiogram, thorax X rays and abdominal ultrasound were unremarkable. Table 1 illustrates the initial arterial blood gases, electrolytes and renal function tests. Dapagliflozin, losartan and simvastatin were discontinued. The patient continued receiving 1 litre of balanced electrolyte solutions each 8 hours, and a continuous insulin infusion for two more days. Cephoxitine $2 \mathrm{~g}$ each 12 hours was initiated due to the suspicious of a urinary infection. The metabolic acidosis reverted in 48 hours $\left(\mathrm{pH} 7.42, \mathrm{pCO}_{2} 16.6 \mathrm{mmHg}\right.$, bicarbonate $11.0 \mathrm{mmo} / \mathrm{L}$ ) and glycemia ranged between 180 to $230 \mathrm{mg} / \mathrm{dL}$. Intravenous insulin infusion was discontinued and subcutaneous human insulin was initiated. On the second day the patient developed hypokalemia and acute kidney failure. The blood urea nitrogen and creatinine concentrations increased to $43.0 \mathrm{mg} / \mathrm{dL}$ and $2.6 \mathrm{mg} / \mathrm{dL}$, respectively. Another urine smear showed few granular casts and eritrocyturia. The haemoglobin dropped to $11.4 \mathrm{~g} / \mathrm{dL}$ and the white blood cell count gradually decreased to $11.1 \times 10^{3} \mu \mathrm{L}$. Five days later when the patient was stable she was referred to Hospital CIMA for further management where a basal bolus regimen with insulin analogues was started. The renal function gradually normalized and the haemoglobin increased. Also, the C-peptide level was of $1.13 \mathrm{ng} / \mathrm{mL}(0.9-7.10)$ with a concomitant glucose level of $150 \mathrm{mg} / \mathrm{dL}$.

\section{Discussion and Conclusion}

This elderly fragile patient with long lasting T2DM recently treated with SGLT-2i developed DKA. Myocardial infarction, heart failure, acute intra-abdominal infection was not documented. At presentation the patient had severe metabolic acidosis, and hemodynamic instability. These conditions resolved within 48 hours with insulin and fluid replacement therapy [17]. However, while the patient was still in the local hospital, hypokalaemia, anemia and acute kidney failure occurred. Hypokalaemia was clearly the result of inadequate potassium replacement. As the patient was not anemic before admission and there was no evidence of bleeding during this acute episode, dilution of haemoglobin was likely the cause of the reduction in hematologic parameters. The acute kidney failure was probably due to hypovolemia aggravated by the angiotensine II blocker. These agents in the presence of volume depletion can prolong hypotension and may contribute to kidney failure. In addition, since infections can precipitate DKA [17] the physician's in-charge of the patient in the local hospital considered reasonable to employ antibiotics.

We received the patient at Hospital CIMA after 5 days of treatment when most the acute complications were resolved. She was discharged 5 days later receiving a basal bolus regimen with insulin analogues, continued with her usual antihypertensive and lipid lowering treatment. Regular contact with the patient and her family has been maintained over the last 6 months.

SGLT2 inhibitors improve glycemic control by inhibiting glucose reabsorption at the proximal renal tubule [1-4]. SGLT-2i also reduces glucose stimulated insulin secretion and diminishes insulin concentrations [1-4]. In response to a lower insulin inhibition and suppression of SGLT2 receptors found in the alpha cells, glucagon concentrations increase [18,19]. Alterations in insulin/glucagon ratio can lead to exaggerated lipolysis from adipose tissue and increased ketogenesis [19-21]. Under these conditions, diabetic patients receiving SGLT2i have an increased the risk for DKA [18-21]. Of note, during the two weeks prior to the trip, when the patient was receiving the new medications, no improvements in glucose control were observed. However she remained clinically stable. In this case, based on the pathophysiology of DKA associated with SGLT-2i [1821], it seems unlikely that the DPP-4i had a role in the development of DKA. DKA was conceivable precipitated by reduction in carbohydrate intake, prolonged fasting and ethanol intake in the background of insulin deficiency, as the C-peptide concentration was not elevated in the presence of hyperglycemia.

We recently reported a case of DKA in a type 1 diabetic male in whom insulin provision was marked reduced after initiation of SGLT2 $[22,17]$. SGLT2i-associated DKA could occur at any duration of SGLT2i use $[22,23]$ as it was seen in our case report.

DKA associated with SGLT-2i is uncommon. A meta-analysis of randomized controlled clinical trials reported an unimportant effect of the medications on the presence of DKA. After the initial warning made by the FDA the incidence of SGLT2i-associated DKA were less than 1/1000 in controlled trials and 1.6/1000 person-years in cohort studies and a recently a report of nationwide population based cohort 
from Korea, the risk of hospitalization for DKA was not increased in those treated with SGLT2 inhibitor $v s$ DPP4 users [22,23].

It is important to highlight that polypharmacy in the elderly, especially with borderline renal or hepatic function and an unknown pharmacologic interaction increases the risk of complications [24-26]. Furthermore, particular attention must be exercised to avoid liquid overload and a careful replacement of electrolytes in elderly patients with DKA [17].

Finally, care must be paid when fragile T2DM patients change their prescription and in particular if SGLT-2 are involved in this change. In such cases it is recommended that patients must report any suspicious manifestation of DKA and to monitor ketone levels if they become sick [25].

\section{References}

1. Musso G, Gambino R, Cassader M, Pagano G (2012) A novel approach to control hyperglycemia in type 2 diabetes: sodium glucose co-transport (SGLT) inhibitors: sytematic review and metaanalysis of randomized trials. Ann Med 44: 375-393.

2. Vallon V (2015) The mechanisms and therapeutic potential of SGLT-2 inhibitors in diabetes mellitus. Annu Rev Med 66: 255-270.

3. Plosker GL (2014) Canagloflozin: A Review of its use in patients with type 2 diabetes mellitus. Drugs 74: 807-824.

4. Sha S, Devineni D, Ghosh A, Polidori D, Chien S, et al. (2011) Canagliflozin, a novel inhibitor of sodium glucose co-transporter 2 , dose dependently reduces calculated renal threshold for glucose excretion and increases urinary glucose excretion in healthy subjects. Diabetes Obes Metab 13: 669-672.

5. Garber AJ, Abrahamson MJ, Barzilay JI, Blonde L, Bloomgarden ZT, et al. (2018) Consensus Statement by the American Association of Clinical Endocrinologists and American College of Endocrinology on the Comprehensive Type 2 Diabetes Management Algorithm - 2018 Executive Summary. Endocr Pract 24: 91-120.

6. Liu XY, Zhang N, Chen R, Zhao JG, Yu P (2015) Efficacy and safety of sodium glucose cotransporter 2 inhibitors in type 2 diabetes: a meta-analysis of randomized controlled trials for 1 to 2 years. $J$ Diabetes Complications 29: 1295-1303.

7. Zinman B, Wanner C, Lachin JM, Fitchett D, Bluhmki E, et al. (2015) Empagliflozin, cardiovascular outcomes, and mortality in type 2 diabetes. N Engl J Med 373: 2117- 2128.

8. Wanner C, Inzucchi SE, Lachin JM, Fitchett D, Eynatten MV, et al. (2016) Empagliflozin and Progression of Kidney Disease in Type 2 Diabetes. N Eng J Med 375: 323-334.

9. Neal B, Perkovic V, Mahaffey KW, de Zeeuw D, Fulcher G, et al. (2017) Canagliflozin and cardiovascular and renal events in type 2 diabetes. N Engl J Med 377: 644-657.

10. John $M$, Cerdas $S$, Violante $R$, Deeroochanawong $C$, Hassanein $M$, et al. (2016) Efficacy and safety of canagliflozin in patients with type 2 diabetes mellitus living in hot climates. Int J Clin Pract 70: 775-785.

11. USFDA (2015) FDA Drug Safety Communication: FDA warns that SGLT2 inhibitors for diabetes may result in a serious condition of too much acid in the blood. Maryland, USA.
12. Jaberi A, Seth B, Steenkamp D, Alexanian S, Borkan SC, et al. (2016) Sodium-Glucose Cotransporter 2 Inhibitors and Euglycemic Diabetic Ketoacidosis: Metabolic Acidosis with a Twist. Clin Diabetes 34: 214216.

13. Peters AL, Buschur EO, Buse JB, Cohan P, Diner JC, et al. (2015) Euglycemic diabetic ketoacidosis: a potential complication of treatment with sodium-glucose co-transporter 2 inhibition. Diabetes Care 38: 1687-1693.

14. Rosenstock J, Ferrannini E (2015) Euglycemic diabetic ketoacidosis: a predictable, detectable, and preventable safety concern with SGLT2 inhibitors. Diabetes Care 38: 1638-1642.

15. Taylor SI, Blau JE, Rother KI (2015) SGLT2 inhibitors may predispose to ketoacidosis. J Clin Endocrinol Metab 100: 2849-2852.

16. Burke KR, Schumacher CA, Harpe SE (2017) SGLT2 Inhibitors: A Systematic Review of Diabetic Ketoacidosis and Related Risk Factors in the Primary Literature. Pharmacotherapy 37: 187-194.

17. Monami M, Nreu B, Zannoni S, Lualdi C, Mannucci E (2017) Effects of SGLT-2 inhibitors on diabetic ketoacidosis: A meta-analysis of randomised controlled trials. Diabetes Res Clin Pract 130: 53-60.

18. Kitabchi AE, Umpierrez GE, Miles JM, Fisher JN (2009) Hyperglycemic crisis in adult patients with diabetes. Diabetes Care 32: 1335-1343.

19. Maruyama H, Hisatomi A, Orci L, Grodsky GM, Unger RH (1984) Insulin within islets is a physiologic glucagon release inhibitor. J Clin Invest 74: 2296-2299.

20. Bonner C, Kerr-Conte J, Gmyr V, Queniat G, Moerman E, et al. (2015) Inhibition of the glucose transporter SGLT2 with dapaglifozin in pancreatic alpha cells triggers glucagon secretion. Nat Med 21: 512517.

21. Qiu H, Novikov A, Vallon V (2017) Ketosis and diabetic ketoacidosis in response to SGLT-2 inhibitors: Basic mechanisms and therapeutic persepectives. Diabetes Metab Res Rev 33: 1-9.

22. Jiménez-Montero JG, Mora-Aguilar CJ, Chen-Ku CH (2018) Diabetic Ketoacidosis in a patient with type 1 diabetes mellitus treated with low insulin in combination with empafloflozin. ACE Clinical Case Rep 4: e505-e508.

23. Kim YG, Jeon JY, Han SJ, Kim DJ, Lee KW, et al. (2018) Sodium-glucose co-transporter-2 inhibitors and the risk of ketoacidosis in patients with type 2 diabetes mellitus: A nationwide population-based cohort study. Diabetes Obes Metab 20: 1852-1858.

24. Ahmed M, McKenna MJ, Crowley RK (2017) Diabetic ketoacidosis in patients with type 2 diabetes recently commenced on SGLT-2 inhibitors: An ongoing concern. Endocr Pract 23: 506-508.

25. Handelsman Y, Henry R, Bloongarden ZT, Dagogo-Jack S, DeFronzo RA, et al. (2016) American Association of Clinical Endocrinologists and American College of Endocrinology Position Statement on the association of SGLT-2 inhibitors and diabetic ketoacidosis. Endocr Pract 22: 753-762.

26. Maher RL, Hanlon J, Hajjar ER (2014) Clinical Consequences of Polypharmacy in Elderly. Expert Opin Drug Saf 13: 57-65. 